\title{
The big ecological questions inhibiting effective environmental management in Australia
}

\author{
S. R. MORTON, ${ }^{1 \star}$ O. HOEGH-GULDBERG,${ }^{2}$ D. B. LINDENMAYER, ${ }^{3}$
} M. HARRISS OLSON,${ }^{4}$ L. HUGHES, ${ }^{5}$ M. T. McCULLOCH,${ }^{6}$ S. McINTYRE, ${ }^{7}$ H. A. NIX, ${ }^{3}$ S. M. PROBER,${ }^{8}$ D. A. SAUNDERS,${ }^{7}$ A. N. ANDERSEN,${ }^{9}$ M. A. BURGMAN,${ }^{10}$ E. C. LEFROY,${ }^{11}$ W. M. LONSDALE,${ }^{12}$ I. LOWE ${ }^{13}$ A. J. McMICHAEL, ${ }^{14}$ J. S. PARSLOW,${ }^{15}$ W. STEFFEN, ${ }^{3}$ J. E. WILLIAMS ${ }^{16}$ AND J. C. Z. WOINARSKI ${ }^{17,18}$ ${ }^{1}$ CSIRO Sustainable Ecosystems, PO Box 2111, Alice Springs, NT 0871, Australia (E-mail: steve.morton@csiro.au), ${ }^{2}$ Centre for Marine Studies, University of Queensland, St Lucia, ${ }^{13}$ School of Science, Griffith University, Nathan, Queensland, ${ }^{3}$ Fenner School of Environment and Society, Australian National University, ${ }^{6}$ Research School of Earth Sciences, Australian National University, ${ }^{7}$ CSIRO Sustainable Ecosystems, ${ }^{12}$ CSIRO Entomology, ${ }^{14}$ National Centre for Epidemiology and Population Health, Australian National University, Canberra ACT, ${ }^{4}$ National Business Leaders Forum on Sustainable Development, Gundaroo, ${ }^{5}$ Department of Biological Sciences, Macquarie University, North Ryde, New South Wales, ${ }^{8}$ CSIRO Sustainable Ecosystems, Wembley, Western Australia, ${ }^{9}$ CSIRO Sustainable Ecosystems, Winnellie, ${ }^{17}$ Northern Territory Department of Natural Resources, Environment and the Arts, Palmerston, ${ }^{18}$ School for Environmental Research, Charles Darwin University, Casuarina, Northern Territory, ${ }^{10}$ Department of Botany, University of Melbourne, Parkville, Victoria, ${ }^{11}$ Centre for Environment, University of Tasmania, ${ }^{15}$ CSIRO Marine and Atmospheric Research, Hobart, and ${ }^{16}$ NRM Insights, Ulverstone, Tasmania, Australia

\begin{abstract}
The need to improve environmental management in Australia is urgent because human health, well-being and social stability all depend ultimately on maintenance of life-supporting ecological processes. Ecological science can inform this effort, but when issues are socially and economically complex the inclination is to wait for science to provide answers before acting. Increasingly, managers and policy-makers will be called on to use the present state of scientific knowledge to supply reasonable inferences for action based on imperfect knowledge. Hence, one challenge is to use existing ecological knowledge more effectively; a second is to tackle the critical unanswered ecological questions. This paper identifies areas of environmental management that are profoundly hindered by an inability of science to answer basic questions, in contrast to those areas where knowledge is not the major barrier to policy development and management. Of the 22 big questions identified herein, more than half are directly related to climate change. Several of the questions concern our limited understanding of the dynamics of marine systems. There is enough information already available to develop effective policy and management to address several significant ecological issues. We urge ecologists to make better use of existing knowledge in dialogue with policy-makers and land managers. Because the challenges are enormous, ecologists will increasingly be engaging a wide range of other disciplines to help identify pathways towards a sustainable future.
\end{abstract}

Key words: Australian ecology, environmental management, knowledge gaps.

\section{INTRODUCTION}

Many commentators and reports have recently pointed to the worrying status and trends of Australia's natural resources. The first comprehensive assessment of landscape health and biodiversity at a continental scale confirms these patterns (National Land and Water Resources Audit 2000a,b; 2001; 2002a,b). The Audit provided a basis for the 2006 State of Environ-

${ }^{\star}$ Corresponding author.

Accepted for publication May 2008. ment Report, an independent national stocktake (Beeton et al. 2006). In commentary on the Report, Cork et al. (2006) noted that 'despite large investments and some promising responses, biodiversity in Australia continues to decline'. Ward and Butler (2006) stated that 'we may still be facing the decline of important assets and features of ocean and coastal ecosystems'. Harris (2006) wrote that 'many indicators show that aquatic ecosystems and biodiversity are degraded across large areas of the continent'. The challenge is urgent because of the fundamental dependence of human society on the environmental resource 
base. Human health, well-being and social stability all depend ultimately on maintenance of life-supporting ecological processes. As the challenge is enormous, ecologists must work with a wide range of other disciplines to help develop pathways towards a sustainable future.

These challenges are not confined to Australia: human populations are having substantial impacts worldwide on ecosystems at all scales, posing unprecedented threats to future human well-being and raising serious concerns about humanity's collective capacity to maintain development (UN Development Program 2007; UN Environment Programme 2007). The questions posed will increasingly require a multidisciplinary approach to environmental management, from adaptive management and institutional analysis through to the dynamics of socioeconomic and biophysical systems. Many ecologists are motivated to contribute to resolution of such questions (e.g. Saunders et al. 1993; Lindenmayer 2007). Although ecological insights do not always readily find their way into policy, science remains a significant contributor to improved environmental management. While the search continues for more effective policy development and governance in natural resource management (e.g. Botterill \& Fisher 2003; Campbell \& Schofield 2006; Hussey \& Dovers 2007), it is vital that ecology provides the most objective advice possible on priorities for improved knowledge. The present paper attempts to do so.

Our inquiry was stimulated by the example of Sutherland et al. (2006) who identified 100 ecological questions of importance in the UK. As with those authors, we begin from the assumption that it is the scientific community's responsibility to advise as objectively as possible on where uncertainty is greatest, and where knowledge is sufficient to act. This paper brings together the experience of 20 scientists to identify first those areas that are hindered by a current inability of science to answer basic questions, and second those fields of environmental management in Australia where knowledge is not a major barrier to improved policy and management.

\section{METHODS}

The 20 co-authors represent many areas of ecology in relation to Australia's environmental management needs. Among ourselves, we canvassed opinion on knowledge needed to mitigate each threatening process, adapt to its consequences and act in policy and management terms. We gradually converged on priority questions representing fundamental barriers to realization of improved environmental policy and management. By implication, these debates identified areas of knowledge where we concluded that research was of lower priority. However, the purpose of this paper is to focus on questions requiring fresh research, and so we mention only in passing those fields where knowledge seems to be adequate for policy and management application. Our inquiry took us in a different direction from Sutherland et al. (2006); rather than allowing for a proliferation of questions, we honed our questions down to a bare minimum. Our product is inevitably a summation of the opinions of its authors.

We scanned previous summaries of the threatening processes affecting Australia (Burgman \& Lindenmayer 1998; Morton et al. 2002; Beeton et al. 2006; Fischer et al. 2007b; Lindenmayer 2007; Raven \& Yeates 2007) and grouped them under two broad headings - global issues and issues of particular significance in Australia. Our objective, then, was to ask which processes are too poorly understood to be effectively acted upon. The only purpose of the groupings is to provide a framework for generating questions.

Global issues are as follows.

A. Integrating ecosystem management with human social systems

B. Climate change

C. Ocean acidification

D. Coastal inundation

These global issues play out in a particular Australian context. Australians are stewards of the driest inhabited continent with its low soil fertility and high climatic variability; as a result, we cannot always rely on generic solutions from science in other parts of the world in dealing with certain integrative challenges of environmental management. It is for this reason that the issue of climate change is peculiarly important for Australia. Furthermore, ocean acidification and coastal inundation provide especially big challenges given that Australians live predominantly in coastal settlements. Finally, resolution of all these issues through policy needs to reflect the fact that Australia is one of the most highly urbanized nations in the world.

Issues requiring a particularly Australian focus are as follows.

E. Alteration, degradation and replacement of natural habitats

F. Invasive species

G. Altered fire regimes

H. Water extraction

I. Urban development and industrial pollution

\section{RESULTS}

\section{A. Integrating ecosystem management with human social systems}

It is counterproductive to view social and ecological systems separately when their intimate links demand 
integration; research itself should be intimately connected with policy, management, on-ground implementation and human livelihoods. Participatory research, co-production of knowledge (including indigenous knowledge) and adaptive management are central to this way of thinking (Head et al. 2005; Campbell \& Schofield 2006; Fischer et al. 2007b; Reynolds et al. 2007; Williams 2007). Scientists will doubtless continue developing approaches in which both research and management are oriented around 'learning by doing'. Progress towards sustainability may be compromised by lack of ecological input, but in many situations the constraint is actually the lack of links between ecology and resource economics, governance, institutional design, policy and management, highlighting the need to integrate the humanities with ecology. Ecologists will play a particular role in such integration, for example, by advising on the maintenance of resilience or facilitation of transformation (Abel et al. 2003; Fischer et al. 2007a; Walker \& Salt 2006). These considerations lead to the following questions.

1. What integrated strategies and tools will help support adaptive management of socioecological systems undergoing rapid change?

2. How much change in different ecosystems can be tolerated in the cycling of carbon, nutrients, water and in biodiversity, if socioecological resilience is to be maintained and ecosystem services are to continue being delivered, and at what point should management aim to effect transitions to new states if maintenance proves impracticable?

3. How can natural ecosystems be valued, such that financial incentives encourage their maintenance and the external environmental costs of primary production are incorporated into the prices of goods?

A second element here concerns connections between environment and human populations, for example through analyses of ecological footprint (Foran \& Poldy 2002), assessment of impact as a product of population, affluence and technology (Chertow 2001; Steffen et al. 2004), and analysis of connections between ecosystem functioning, environmental quality and human health (McMichael 2008). Movements in human populations as a result of climate change may further influence these challenges in Australia (section B). One broad question requires further ecological input.

4. How does knowledge of the relationships among human population size, economic systems, technology, institutions, ecological footprint and environmental change need to be expressed to help society define sustainability goals?

Finally, integration of environmental management with socioeconomic frameworks demands effective measurement of environmental state, trend and per- formance, to provide feedback to policy-makers about management action and environmental response. As yet environmental monitoring rarely matches this need (Field et al. 2007); we note, in contrast, that society seems to assume effective economic monitoring.

5. How can data sets be rigorously gathered, analysed and reported to establish environmental trend, critical thresholds and feedbacks to management?

\section{B. Climate change}

Climate change will act in synergy with other factors to produce numerous direct and indirect effects (Hughes 2003; Natural Resource Management Ministerial Council 2004; Westoby \& Burgman 2006; Poloczanska et al. 2007; Dunlop \& Brown 2008).

- Ocean acidification

- Coastal inundation

- Range shifts of species, range fragmentation or shrinkage, extinctions and changes in the structure of ecosystems

- Decoupling of established interactions between species through altered timing of life cycles

- Potentially greater vulnerability to biological invasions

- Additional alteration to fire regimes

- Impacts on production systems, including shifts in geographical location

- Movements, health, well-being and livelihoods of people

- Changes in linkages between ecological and socioeconomic systems

If management is to respond effectively to the impact of climate change on ecosystem function, the distribution of species and community composition, then long-standing gaps in knowledge of the drivers of ecosystems and the distribution of Australian species need filling (Hughes 2003). Assuming development of meaningful environmental monitoring (question 5), three questions seem compelling.

6. How can the global circulation models that are used to predict climate change be down-scaled to match ecological responses at the landscape level in Australia?

7. How can potentially non-linear responses to climate and substrate, and biotic interactions, be better understood and incorporated into improved analysis of ecosystems and distribution of species?

8. How can management attempt to withstand unwanted effects in ecosystems undergoing change in composition, and at what point should it attempt to provide options for ecosystems to adjust to new states?

With invasive species, climate change reinforces the need for research emphasis to shift from responding to invaders towards early anticipation and suppression of 
threats (Department of Agriculture, Fisheries and Forestry 2008). Efforts should encompass enhanced integration of risk diagnosis, control systems, policy and research. The question has particular relevance to human health.

9. How can we devise and implement an Australian early detection system for potential invaders (including new weeds, pests, pathogens and diseases as well as genetically modified organisms and native species), and a response system based on prediction of likely entry, establishment, spread and impact?

Ecological responses to fire regimes in Australia are relatively well known (section G). However, insufficient work has been done on dynamic vegetation models that would allow analysis of the following question (Cary et al. 2003).

10. What alterations in fire regimes are likely with climate change, and what interventions would be practicable for the maintenance of biodiversity and ecosystem function?

Ecologists are well aware that episodic events are exceedingly important in affecting the structure and functioning of Australian ecosystems (Westoby 1980; Stafford Smith \& Morton 1990; Orians \& Milewski 2007; Stafford Smith \& McAllister 2008); with care, these well-understood relationships should allow retrospective analyses to be used to project future interactions with climate change. Such interactions in marine systems, however, deserve more research attention. Changes in ocean circulation have the potential to modify the supply of nutrients into surface waters and thence marine primary production; and coastal ecosystems are dramatically affected by extreme events such as cyclones. Shifts in the frequency and intensity of such events could radically modify marine ecosystems and their associated ecosystem services.

11. How will alterations in extreme events interact with changes in ocean circulation and production to modify marine ecosystems and biodiversity under climate change, and how might management respond?

The relationships between production systems, land capability and climate are reasonably well understood because Australia's success as an agricultural nation has depended upon such knowledge (Henzell 2007) although with substantial external costs still emerging (question 3). Climate change will force major changes in the distributions and types of resource use, with substantial yet poorly analysed consequences for environmental management. In particular, questions remain about the implications of climate change for current developments in 'ecosystem-based' fisheries management.

12. What environmental impacts on production and resource-use systems are likely from shifts induced by climate change, where will they occur and how could their location and extent be managed to satisfy both environmental and production objectives?

\section{Ocean acidification}

The world's oceans will experience increasing acidification in future because addition of relatively small amounts of $\mathrm{CO}_{2}$ to the atmosphere causes substantial changes to carbonate concentrations in seawater (Raven et al. 2005). As a result, the physiology of marine organisms can be affected through acidosis (Raven et al. 2005), but how these impacts will affect ecological systems and fisheries is unknown. A further effect will be reduction in carbonate ion concentrations, directly influencing calcifying organisms such as corals in tropical seas (Hoegh-Guldberg 2005; HoeghGuldberg et al. 2007), and the many invertebrates and phytoplankton of temperate southern waters. Given that $40 \%$ of Australia's coastline is lined by coral reefs, this is serious for marine biodiversity as well as for fishing and tourism. Changes to primary producers could also have flow-on impacts on ecological organization; for example, changes to Southern Ocean productivity may have implications for the biological carbon pump which could in turn lead to a reduction in oceanic uptake of $\mathrm{CO}_{2}$.

13. How and where will acidification interact with other climatic changes (e.g. increasing ocean temperatures) to change ecological function in marine ecosystems, and how might management counter the effects?

14. Will buffering from existing coastal 'carbonate' structures and coral reefs diminish as a result of rising acidity, what would be the implications for biodiversity and for physical protection and how might management counter the effects?

\section{Coastal inundation}

Sea level rise is accelerating and Australia and its neighbours will need to adapt rapidly in coming decades (Church \& White 2006). Although the various zones of new coastlines can be mapped, uncertainties will remain in the rate and magnitude of future changes in sea level. It may be possible, using current technologies, to assist the migration of coastal forests, wetlands, salt marshes and mangroves under conservative estimates of sea level rise (approximately 0.4$0.6 \mathrm{~m}$ rise by 2100 ). However, the scale and urgency of the problems under more drastic scenarios $(>1 \mathrm{~m}$ rise by 2100) suggest that added effort is needed.

15. How will coastal ecosystems respond to the direct effects of sea level rise, to the indirect 
impacts of reduced reef accretion and changing sediment, nutrient and salinity regimes, and to feedbacks between ecosystems and physical processes?

16. How will key fishery species be affected by changes to nursery grounds as coastal ecosystems undergo re-organization?

17. How will Australia's coastal aquifers and groundwater resources respond to sea level rise through effects such as saltwater intrusion, and how can water quality be maintained under these conditions?

Equally significant questions relate to human infrastructure in low-lying coastal areas; this challenge is mentioned in section I.

\section{E. Alteration, degradation and replacement of natural habitats}

In relation to harvesting of natural resources from semi-natural ecosystems, management principles to avoid over-exploitation, minimize loss of biodiversity and maintain primary production are relatively well understood (Jackson et al. 2001; Lindenmayer \& Franklin 2002; McIntyre et al. 2002; Pandolfi et al. 2003; Reynolds et al. 2007). There will be ongoing need for more effective application of these principles, especially with emphasis on interactive effects on other ecological processes (e.g. control of invasive species, by-catch in fisheries). Australia faces challenging problems in setting sustainable harvesting rates because of existing climatic variability, and question 12 notes that such challenges may multiply with climate change. Because barriers to application of these principles rest more in the socioeconomic domain than in a lack of ecological knowledge, progress is required in such issues as the valuing of resources (question 3 ).

Much is already known about degradation and replacement of natural habitats as threatening processes. Ecologists are able to contribute quantitative knowledge on the effects of degradation and destruction of habitats on biodiversity loss, vulnerability to invasion by weeds and pests, soil erosion, salination, water quality, nutrient leakage, and damage to carbon cycles, hydrological cycles, ecosystem resilience and agricultural and fishing productivity (McKeon et al. 1990; Jackson et al. 2001; Pandolfi et al. 2003; Soulé et al. 2004; Gleeson \& Dalley 2006). However, processes for reversing or ameliorating such trends are less well developed, and the design of landscape networks for maintenance of biodiversity and ecosystem services is poorly understood (Soulé et al. 2004; Lindenmayer \& Fischer 2006; Menninger \& Palmer 2006).

18. What ecological processes can be manipulated to reverse and restore the loss of biodiversity and

Journal compilation (C) 2009 Ecological Society of Australia ecosystem function in degraded landscapes, and in particular how can connectivity best be managed to prevent further loss?

Intensive agriculture produces large changes in ecological processes. The numerous on-site effects are well known, such as soil erosion and biodiversity loss, and off-site effects have become increasingly obvious, including impacts on water quality through dryland and irrigation salinity, eutrophication, sedimentation, altered flow regimes, agri-chemical run-off and the decline of biodiversity through landscape-scale effects (Hobbs \& Saunders 1992; National Land \& Water Resources Audit 2000a). Mitigation and policy are usually technically challenging and always socially and economically complex. Effort is required to develop practices to minimize 'leakiness' of agroecosystems, through the adoption of farming systems better adapted to the tolerances of these ecosystems (Lefroy et al. 2005; Pannell et al. 2006). In regions where safe levels of intensification have been exceeded, methods are required to encourage the adoption of alternative land-use and management systems, including through stewardship payments for environmental services. All of these challenges are playing out in the context of climate change. Our conclusion is that the ecological knowledge required to help develop more effective environmental policy and management is encompassed in questions $1,2,3$, 9 and 12 .

\section{F. Invasive species}

Much is also known about the threats posed by invasive species (Burgman \& Lindenmayer 1998; Lonsdale 1999; Mack et al. 2000; Williams \& West 2000). Solutions lie in threat reduction through risk analysis, strict quarantine controls, rapid early eradication, chemical and biological control of highly invasive species that get through these safety nets, and maintenance or enhancement of resistance by native communities to invasion (McLeod 2004; Australian Biosecurity Group 2005; D’Antonio \& Chambers 2006). Resistance to invasion is usually weakened when disturbance regimes are altered and under conditions of habitat degradation; hence, knowledge from answers to questions $8-11$ is relevant. Research into integration of biological control with chemical and manual techniques is still required; providing such control needs resources but is not profoundly limited by knowledge. Current debates (e.g. Stohlgren et al. 2003) about the relationship between diversity and invasibility are scientifically significant, but unlikely to lead to rapid increases in ability to manage invasions. For us, question 9 covers the highest-priority need for research that will reduce the impact of invaders on biodiversity. 


\section{G. Altered fire regimes}

Australia possesses high levels of indigenous and scientific knowledge of fire behaviour and impacts (Bradstock et al. 2002; Cary et al. 2003), although this has not necessarily translated into improved management. The outstanding problems with fire management lie in trading-off in tensions between management for protection of human life and property, and management for other environmental purposes. Climate change will intensify these challenges (question 10). Effective on-ground management needs information specific to different ecological communities. Hence, we recognize one critical question.

19. How can the interactive impacts on biodiversity and ecosystem function of altered fire regimes and natural resource use be quantified and incorporated into management?

\section{H. Water use, extraction and management}

Water extraction on the driest inhabited continent on Earth has led to substantial changes in the structure and function of aquatic ecosystems, with consequent loss of ecosystem services and species from surface waters, groundwater-dependent ecosystems and wetlands (Hussey \& Dovers 2007). Accelerating impacts seem likely under conditions of increased variability and decreases in rainfall due to climate change; indeed, it is very likely that some human responses to climate change, such as construction of new dams, will exacerbate existing environmental problems. Continued over-exploitation of groundwater and decreased recharge rates in many areas could diminish the resource. Problems are also likely in coastal environments, where demand for water will intensify (question 17). Again lack of ecological knowledge is not the primary gap, and the policy-related questions 2-3 encompass the major issues for more effective environmental management (Hussey \& Dovers 2007). One outstanding question remains.

20. How can we design and implement environmental flows to ensure resilience of rivers, wetlands and estuaries, in light of changing climate, shifting patterns of land use and native vegetation, and changing human demands?

\section{Urban development and industrial pollution}

Urban development increases water extraction, encourages some invasive species and opens entry pathways to others, creates nutrient enrichment, produces high volumes of wastes and storm-water, and as a form of intensive land use causes loss of biodiversity (Newton 2008). Can urban design be improved to support environmental management and conservation of resources and biodiversity? How might Australian cities move toward more energy- and water-efficient design? How can cities contribute to biodiversity conservation within their regions? How can coastal development occur safely with respect to maintenance of ecological function? The following question adds to our discussion under climate change and coastal inundation.

21. How can urban and peri-urban intensification be designed to allow both for adaptation of human settlements to climate change and improved environmental management?

Pollution encompasses global rather than peculiarly Australian problems, but not enough is known locally. For example, understanding of atmospheric pollution, run-off to estuaries, waste flows and contaminated landfill and groundwater is patchy in extent and application. Because many pollutants such as endocrine disrupters have human health impacts there may be relatively rapid application of knowledge; however, many may also have lesser-known ecological effects. Engineering solutions usually require some ecological input. We conclude here that one question deserves particular attention.

22. How can ecological knowledge be incorporated more intimately into industrial life cycle analysis, recycling and water re-use?

\section{DISCUSSION}

Of the 22 questions above, about half are directly related to climate change (seven questions) and the associated processes of ocean acidification and coastal inundation (a further five). Is our emphasis on the impacts of climate change simply due to the fact that it has become such an important public debate during the last few years; in short, is our emphasis on this matter unjustified? We think not. The threats posed by climate change have been identified for over 20 years (Peters \& Darling 1985; Williams et al. 1994), but support has not been in place for the magnitude of research effort required. Clearly there has been growing scientific and community realization about the speed of change and the likelihood that a changing climate could exacerbate existing environmental problems. This does not necessarily mean that climate change is the most threatening process; rather, it is where ecological science is less able to provide options for dealing with rapid environmental change, due to poor understanding of the systemic complexity of the processes involved. Consequently, there is a large amount of ground to be made up.

Is our conclusion correct that relatively few big ecological questions are still to be answered about threatening processes such as the alteration, degradation and 
replacement of natural habitats, invasive species and altered fire regimes? Of course, we recognize that there are some outstanding knowledge gaps in these areas. Nevertheless, we conclude that, in broad terms, sufficient ecological information is available for policy and management to proceed with effective scientific input.

If uptake of ecological understanding is not occurring, ecologists need to ask why. Lack of uptake in some areas may be due to failure by ecological science to frame options in the most effective manner, to form sufficiently powerful links with resource economics and natural resource governance, or to develop adequate connections with the policy-making and management communities. In our view it is vital that ecologists confront this need for increased dialogue with their policy colleagues. Hamel and Prahalad (1989) contend that too many scientists have a 'strategy of hope' that their work will be useful for policymakers. It seems to us that ecologists should continue building capacity to supply reasonable inference from existing knowledge, allowing for adaptive management to refine further application. Whatever conclusion one comes to on these matters, we argue that ecologists must strive even more to make their work relevant to policy and management. We do not imply that this is a task suited to all ecologists; rather, it needs respecting by all.

In emphasizing 'big' questions we are certainly not implying that the 'small' issues involved in translating current ecological understanding into practical solutions for land managers are somehow unimportant. Such matters are by no means small. Even when current ecological knowledge finds its way into policy and into on-ground programmes, there remains a huge task in providing detailed and local ecological insight. For example, ecologists know that fire regimes have a huge influence on biodiversity and ecosystem function, but often are not sure exactly what regime to recommend for a particular patch of vegetation, because of competing management objectives and uncertainty about the responses of individual species. In short, the task of translating present ecological knowledge into practical solutions must proceed in concert with the marshaling of effort on the sorts of big questions that form the focus of this paper.

Humans are changing the biosphere at a global scale and no part of the Earth is escaping this influence. Consequently, ecological questions need to be considered within multidisciplinary frameworks that are aimed at sustainability. A further challenge is to foster understanding of the fundamental dependence of human health, well-being and society on the national and global environmental resource base. The challenges are enormous, and ecology must work with a wide range of other disciplines to help develop pathways towards a sustainable future.

\section{ACKNOWLEDGEMENTS}

This inquiry and the collaborative process that has followed were inspired by Terry Root of Stanford University, who first forwarded Sutherland et al. (2006) to MHO. At the initial workshop convened by the National Business Leaders Forum on Sustainable Development, David Waller was instrumental in organizing the summary of the material that has developed into this paper. SRM thanks the staff of CSIRO's Alice Springs laboratory for hospitality. OHG acknowledges the Reef and Rainforest Research Centre and the Coral Reef Targeted Research Program (http://www. coralcoe.org.au) for support. Mark Howden and Mark Stafford Smith commented constructively on the manuscript.

\section{REFERENCES}

Abel N., Cork S., Gorddard R. et al. (2003) Natural Values: Exploring Options for Enhancing Ecosystem Services in the Goulburn Broken Catchment. CSIRO Sustainable Ecosystems, Canberra.

Australian Biosecurity Group (2005) Invasive Weeds, Pests and Diseases: Solutions to Secure Australia. CRC for Pest Animal Control, CRC for Australian Weed Management and WWF - Australia, Canberra.

Beeton R. J. S., Buckley K. I., Jones G. J., Morgan D., Reichelt R. E. \& Trewin D. (2006) Australia State of the Environment 2006. Australian Government, Canberra.

Botterill L. C. \& Fisher M., eds (2003) Beyond Drought in Australia: People, Policy and Perspectives. CSIRO Publishing, Melbourne.

Bradstock R. A., Williams J. E. \& Gill A. M. (2002) Flammable Australia: Fire Regimes and the Biodiversity of a Continent. Cambridge University Press, Cambridge.

Burgman M. A. \& Lindenmayer D. B. (1998) Conservation Biology for the Australian Environment. Surrey Beatty \& Sons, Sydney.

Campbell A. \& Schofield N. (2006) The Getting of Knowledge: A Guide to Funding and Managing Applied Research. Land and Water Australia, Canberra.

Cary G., Lindenmayer D. B. \& Dovers S. (2003) Australia Burning: Fire Ecology, Policy and Management Issues. CSIRO Publishing, Melbourne.

Chertow M. R. (2001) The IPAT equation and its variants; changing views of technology and environmental impact. 7. Industr. Ecol. 4, 13-29.

Church J. A. \& White N. J. (2006) A 20th century acceleration in global sea-level rise. Geophys. Res. Lett. 33, L01602, doi: 10.1029/2005GL024826.

Cork S., Sattler P. \& Alexandra J. (2006) Biodiversity Theme Commentary. [Cited 16 August 2007.] Available from URL: http://www.environment.gov.au/soe/2006/publications/ commentaries/biodiversity/index.html

D’Antonio C. M. \& Chambers J. C. (2006) Using ecological theory to manage or restore ecosystems affected by invasive plant species. In: Foundations of Restoration Ecology (eds D. A. Falk, M. A. Palmer \& J. B. Zedler) pp. 260-79. Island Press, Washington, DC.

Department of Agriculture, Fisheries and Forestry (2008) AusBIOSEC (Australian Biosecurity System for Primary Pro- 
duction and the Environment). [Cited 30 March 2008.] Available from URL: http://www.daff.gov.au/animal-plant-health/ pests-diseases-weeds/biosecurity/ausbiosec

Dunlop M. \& Brown P. R. (2008) Implications of Climate Change for Australia's National Reserve System: A Preliminary Assessment. Department of Climate Change, Canberra.

Field S. A., O’Connor P. J., Tyre A. J. \& Possingham H. P. (2007) Making monitoring meaningful. Austral Ecol. 32, 485-91.

Fischer J., Lindenmayer D. B., Blomberg S., Montague-Drake R. \& Felton A. (2007a) Functional richness and relative resilience of bird communities in regions with different land use intensities. Ecosystems 10, 964-74.

Fischer J., Manning A. D., Steffen W. et al. (2007b) Mind the sustainability gap. Trends Ecol. Evol. 22, 621-4.

Foran B. \& Poldy F. (2002) Future Dilemmas: Options to 2050 for Australia's Population, Technology. Resources and Environment. CSIRO Resource Futures Working Paper 02/01. CSIRO Sustainable Ecosystems, Canberra.

Gleeson T. \& Dalley A. (2006) Land Theme Commentary. [Cited 16 August 2007.] Available from URL: http://www. environment.gov.au/soe/2006/publications/commentaries/ biodiversity/index.html

Hamel G. \& Prahalad C. K. (1989) Strategic intent. Harvard Bus. Rev. 89, 63-76.

Harris G. (2006) Inland Waters Theme Commentary. [Cited 16 August 2007.] Available from URL: http://www. environment.gov.au/soe/2006/publications/commentaries/ biodiversity/index.html

Head L., Trigger D. \& Mulcock J. (2005) Culture as concept and influence in environmental research and management. Conserv. Soc. 3, 251-64.

Henzell T. (2007) Australian Agriculture: Its History and Challenges. CSIRO Publishing, Melbourne.

Hobbs R. J. \& Saunders D. A. (1992) Reintegrating Fragmented Landscapes: Towards Sustainable Agriculture and Nature Conservation. Springer Verlag, New York.

Hoegh-Guldberg O. (2005) Low coral cover in a high-CO2 world. F. Geophys. Res. 110, C09S06, doi: 10.1029/ 2004JC002528.

Hoegh-Guldberg O., Mumby P. J., Hooten A. J. et al. (2007) Coral reefs under rapid climate change and ocean acidification. Science 318, 1737-42.

Hughes L. (2003) Climate change and Australia: trends, projections and impacts. Austral Ecol. 28, 423-43.

Hussey K. \& Dovers S., eds (2007) Managing Water for Australia: The Social and Institutional Challenges. CSIRO Publishing, Melbourne.

Jackson J. B. C., Kirby M. X., Berger W. H. et al. (2001) Historical overfishing and the recent collapse of coastal ecosystems. Science 293, 629-38.

Lefroy E. C., Flugge F. J., Avery A. \& Hume I. (2005) Potential of current plant-based options for the management of dryland salinity: a review. Aust. f. Exp. Agric. 45, 135767.

Lindenmayer D. (2007) On Borrowed Time: Australia's Environmental Crisis and What We must do About it. Penguin Books and CSIRO Publishing, Melbourne.

Lindenmayer D. B. \& Fischer J. (2006) Habitat Fragmentation and Landscape Change: An Ecological and Conservation Synthesis. Island Press, Washington, DC.

Lindenmayer D. B. \& Franklin J. F. (2002) Conserving Forest Biodiversity: A Comprehensive Multi-scaled Approach. Island Press, Washington, DC.

Lonsdale W. M. (1999) Global patterns of plant invasions, and the concept of invasibility. Ecology 80, 1522-36.
Mack R. N., Simberloff D., Lonsdale W. M., Evans H., Clout M. \& Bazzaz F. A. (2000) Biotic invasions: causes, epidemiology, global consequences, and control. Ecol. Appl. 10, 689710 .

McIntyre S., McIvor J. G. \& Heard K. M., eds (2002) Managing and Conserving Grassy Woodlands. CSIRO Publishing, Melbourne.

McKeon G. M., Day K. A., Howden S. M. et al. (1990) Management for pastoral production in northern Australian savannas. F. Biogeog. 17, 355-72.

McLeod R. (2004) Counting the Cost: Impact of Invasive Animals in Australia 2004. Cooperative Research Centre for Pest Animal Control, Canberra.

McMichael A. J. (2008) Public health, the environment and the 21st century: a wider field of vision. Europ. F. Publ. Health. $18,101$.

Menninger H. L. \& Palmer M. A. (2006) Restoring ecological communities: from theory to practice. In: Foundations of Restoration Ecology (eds D. A. Falk, M. A. Palmer \& J. B. Zedler) pp. 88-112. Island Press, Washington DC.

Morton S., Bourne G., Cristofani P., Cullen P., Possingham H. \& Young M. (2002) Sustaining our Natural Ecosystems and Biodiversity: An Independent Report to the Prime Minister's Science, Engineering and Innovation Council. CSIRO Sustainable Ecosystems and Environment Australia, Canberra.

National Land and Water Resources Audit (2000a) Landscape Health in Australia. Australian Government, Canberra.

National Land and Water Resources Audit (2000b) Australian Water Resources Assessment 2000. Australian Government, Canberra.

National Land and Water Resources Audit (2001) Australian Native Vegetation Assessment 2001. Australian Government, Canberra.

National Land and Water Resources Audit (2002a) Australian Catchment, River and Estuary Assessment 2002. Australian Government, Canberra.

National Land and Water Resources Audit (2002b) Australian Terrestrial Biodiversity Assessment 2002. Australian Government, Canberra.

Natural Resource Management Ministerial Council (2004) The National Climate Change Biodiversity Action Plan (2004 2007). Australian Government, Canberra.

Newton P.W., ed. (2008) Transitions: Pathways toward Sustainable Urban Development in Australia. CSIRO Publishing, Melbourne.

Orians G. H. \& Milewski A. V. (2007) Ecology of Australia: the effects of nutrient-poor soils and intense fires. Biol. Rev. 82, 393-423.

Pandolfi J. M., Bradbury R. H., Sala E. et al. (2003) Global trajectories of the long-term decline of coral reef ecosystems. Science 301, 955-58.

Pannell D. J., Marshall G. R., Barr N., Curtis A., Vanclay F. \& Wilkinson R. (2006) Understanding and promoting adoption of conservation practices by rural landholders. Aust. $\mathcal{F}$. Exp. Agric. 46, 1407-24.

Peters R. L. \& Darling J. D. S. (1985) The greenhouse effect and nature reserves. Bioscience 35, 707-17.

Poloczanska E. S., Babcock R., Butler A. et al. (2007) Impacts of climate change on Australian marine life. Oceanogr. Mar. Biol. Ann. Rev. 45, 407-78.

Raven J., Caldeira K., Elderfield H. et al. (2005) Ocean acidification due to increasing atmospheric carbon dioxide. Roy. Soc. Lond. (Special Report) 1-68. 
Raven P. H. \& Yeates D. K. (2007) Australian biodiversity: threats for the present, opportunities for the future. Aust. F. Entomol. 46, 177-87.

Reynolds J. F., Stafford Smith D. M., Lambin E. F. et al. (2007) Global desertification: building a science for dryland development. Science 316, 847-51.

Saunders D. A., Hobbs R. J. \& Ehrlich P. R., eds (1993) Nature Conservation 3: Reconstruction of Fragmented Ecosystems, Global and Regional Perspectives. Surrey Beatty \& Sons, Sydney.

Soulé M. E., Mackey B. G., Recher H. C. et al. (2004) The role of connectivity in Australian conservation. Pac. Conserv. Biol. 10, 266-79.

Stafford Smith D. M. \& Morton S. R. (1990) A framework for the ecology of arid Australia. F. Arid Environ. 18, 255-78.

Stafford Smith M. \& McAllister R. (2008) Managing arid zone natural resources in Australia for spatial and temporal variability - an approach from first principles. Rangel. F. 30, 15-27.

Steffen W., Sanderson A., Tyson P. D. et al. (2004) Global Change and the Earth System: A Planet under Pressure. SpringerVerlag, Berlin.

Stohlgren T. J., Barnett D. T. \& Kartesz J. T. (2003) The rich get richer: patterns of plant invasions in the United States. Front. Ecol. Environ. 1, 11-4.

Sutherland W. J., Armstrong-Brown S., Armsworth P. R. et al. (2006) The identification of 100 ecological questions of high policy relevance in the UK. f. Appl. Ecol. 43, 617-27.
UN Development Program (2007) Human Development Report 2007-2008. Fighting Climate Change: Human Solidarity in a Divided World. [Cited 30 March 2008.] Available from URL: http://hdr.undp.org/en/reports/global/hdr2007-2008/

UN Environment Programme (2007) Global Environmental Outlook: Environment for Development 4. United Nations Environment Programme, Valletta.

Walker B. \& Salt D. (2006) Resilience Thinking: Sustaining Ecosystems and People in a Changing World. Island Press, Washington, DC.

Ward T. J. \& Butler A. (2006) Coasts and Oceans Theme Commentary. [Cited 16 August 2007.] Available from URL: http://www.environment.gov.au/soe/2006/publications/ commentaries/biodiversity/index.html

Westoby M. (1980) Elements of a theory of vegetation dynamics in arid rangelands. Israel F. Bot. 28, 169-94.

Westoby M. \& Burgman M. (2006) Climate change as a threatening process. Austral Ecol. 31, 549-50.

Williams J. (2007) Linking science and practice: the pros and cons of the participatory research model. Ecol. Manage. Restor. 8, 158-9.

Williams J. E. \& West C. (2000) Environmental weeds in Australia and New Zealand: issues and approaches to management. Austral Ecol. 25, 425-44.

Williams J. E., Norton T.W. \& Nix H. (1994) Climate Change and the Maintenance of Conservation Values in Terrestrial Ecosystems. Department of the Environment, Sport and Territories, Canberra. 